\title{
Pengaruh Komitmen Kerja dan Kepuasan Kerja terhadap Kinerja Karyawan PT. Mopoli Raya di Kecamatan Seruway
}

\section{Effect of Work Commitment and Job Satisfaction on Employee Performance of PT. Mopoli Raya in Seruway District}

\author{
Zulkarnen Mora $^{1}{ }^{*}$, Icha Fandayani ${ }^{1}$ \& Agung Suharyanto $^{2}$ \\ ${ }^{1}$ Program Studi Manajemen, Fakultas Ekonomi, Universitas Samudra, Indonesia \\ ${ }^{2}$ Program Studi Administrasi Publik, Fakultas Ilmu Sosial dan Politik, Universitas Medan Area, \\ Indonesia \\ Diterima: 17 September 2020; Direview: 26 September 2020; Dipublish: 17 Oktober 2020 \\ *E-mail: zulkarnen.mora@unsam.ac.id
}

\begin{abstract}
Abstrak
Penelitian bertujuan untuk mengetahui pengaruh komitmen kerja dan kepuasan kerja terhadap kinerja karyawan pada PT. Mopoli Raya. Penelitian ini menggunakan sampel sebanyak 83 responden yang merupakan karyawan tetap dari PT. Mopoli Raya. Metode analisis data menggunakan persamaan regresi linier berganda, uji $t$, uji F serta koefisien determinasi $\left(\mathrm{R}^{2}\right)$. Hasil penelitian menunjukkan bahwa komitmen kerja berpengaruh berpengaruh positif terhadap kinerja dan bila komitmen kerja meningkat satu satuan maka akan meningkatkan kinerja. Kepuasan kerja berpengaruh positif terhadap kinerja dan bila kepuasan kerja meningkat satu satuan maka akan meningkatkan kinerja. Komitmen kerja tidak berpengaruh signifikan terhadap kinerja karyawan, kepuasan kerja berpengaruh signifikan terhadap kinerja karyawan pada PT. Mopoli Raya, maka dapat dinyatakan bahwa variabel komitmen kerja dan kepuasan kerja secara simultan berpengaruh terhadap kinerja karyawan. Dengan demikian, komitmen kerja dan kepuasan kerja mempengaruhi kinerja karyawan PT. Mopoli Raya.
\end{abstract}

Kata Kunci: Komitmen Kerja, Kepuasan Kerja, Kinerja Karyawan

\begin{abstract}
This study aims to determine the effect of work commitment and job satisfaction on employee performance at PT. Mopoli Raya. This study uses a sample of 83 respondents who are permanent employees of PT. Mopoli Raya. Methods of data analysis using multiple linear regression equations, $t$ test, $F$ test and the coefficient of determination (R2). The results showed that work commitment has a positive effect on performance and if work commitment increases by one unit it will increase performance. Job satisfaction has a positive effect on performance and if job satisfaction increases by one unit it will increase performance. Work commitment has no significant effect on employee performance, job satisfaction has a significant effect on employee performance at PT. Mopoli Raya, it can be stated that the variables work commitment and job satisfaction simultaneously affect employee performance. Thus, work commitment and job satisfaction affect the performance of employees of PT. Mopoli Raya.
\end{abstract}

Keywords: Work Commitment, Job Satisfaction, Employee Performance

How to Cite: Mora. Z, Fandayani, I, Suharyanto. A,. (2020). Pengaruh Komitmen Kerja, Kepuasan Kerja Terhadap Kinerja Karyawan PT Mopoli Raya Di Kecamatan Seruway. Journal of Education, Humaniora and Social Sciences (JEHSS). 3 (2): 487-492 


\section{PENDAHULUAN}

Pengelolaan terhadap sumber daya manusia merupakan hal yang penting dalam pencapaian tujuan. Umumnya pimpinan organisasi mengharapkan kinerja yang baik dari masingmasing sumber daya manusia dalam mengerjakan tugas-tugas yang diberikan organisasi. Organisasi menyadari bahwa sumber daya manusia merupakan modal dasar dalam proses pembangunan organisasi, oleh karena itu kualitas sumber daya manusia senantiasa harus dikembangkan dan diarahkan agar tercapainya tujuan yang telah ditetapkan oleh suatu organisasi.

Organisasi salah satu bentuknya adalah perusahaan yang memiliki tujuan pencapaian profit. Perusahaan yang dalam kegiatan sehari-hari sebagai pelaku bisnis dituntut untuk dapat mengambil keputusan yang tepat agar dapat menghadapi persaingan di era globalisasi saat ini. Perusahaan yang mampu melakukan efisiensi, peningkatan mutu dan peningkatan kinerja dapat mempertahankan kelangsungan hidup perusahaan serta mampu untuk dapat terus berkembang. Kondisi tersebut menuntut para pelaku bisnis untuk meningkatkan kinerja yang tidak lepas dari kemampuan dalam perencanaan, pengkoordinasian dan pengendalian berbagai aktivitas dan sumber daya yang dimiliki. Sumber daya salah satunya adalah karyawan. Karyawan menjadi penggerak setiap kegiatan dalam perusahaan.

Karyawan perusahaan dituntut untuk dapat bekerja dalam mencapai tujuan perusahaan. Keberhasilan suatu perusahaan dapat dicapai tidak hanya melalui faktor-faktor keunggulan yang sifatnya bernilai ekonomi, namun juga ditentukan oleh keunggulan kompetitif karyawan sebagai sumber daya manusia. Keunggulan kompetitif perusahaan dapat dicapai jika karyawan dalam sebuah perusahaan dapat bekerja sesuai dengan standar kinerja yang ada sehingga pecapaian tujuan perusahaan sesuai dengan rencana yang telah dibuat sebelumnya. Dengan kinerja karyawan yang tinggi maka akan menghasilkan kinerja perusahaan yang tinggi secara keseluruhan. Namun sebaliknya, jika karyawan memiliki kinerja yang rendah maka kinerja perusahaan rendah secara keseluruhan. Tinggi rendahnya kinerja karyawan berkaitan dengan komitmen, kompensasi, kecerdasan dan kepuasan kerja yang dirasakan masing-masing karyawan.

Kepuasan kerja adalah sikap umum terhadap pekerjaan seseorang yang menunjukkan perbedaan antara jumlah penghargaan yang diterima pekerja dan jumlah yang mereka yakini seharusnya mereka terima. Kepuasan kerja mengekspresikan sejumlah kesesuaian antara harapan seseorang tentang pekerjaannya yang dapat berupa penghargaan yang diberikan perusahaan berupa imbalan atas pekerjaannya.Hal ini dapat dirasakan karyawan yang bekerja di berbagai organisasi perusahaan. Kepuasan kerja yang dirasakan diharapkan dapat meningkatkan kinerja karyawan. Dari hasil penelitian terdahulu pada Dinas Pemberdayaan perempuan Kabupaten Aceh Timur dengan judul Konflik Kerja-Keluarga dan Kepuasan Kerja Pegawai Perempuan: Studi pada Pegawai Negeri Sipil di Aceh Timur didapatkan bahwa bahwa kepuasan kerja memiliki pengaruh yang signifikan terhadap kinerja karyawan, sehingga semakin besar kepuasan kerja karyawan maka semakin tinggi kinerja karyawan yang dimiliki (Mora, dkk, 2017)

Komitmen Kerja merupakan dimensi perilaku yang dapat digunakan untuk menilai kecenderungan pegawai. Komitmen kerja adalah suatu keadaan seorang karyawan yang memihak organisasi tertentu, serta tujuan-tujuan dan keinginannya untuk mempertahankan keanggotaannya dalam organisasi, komitmen kerja memiliki dua komponen penting, yaitu sikap dan kehendak untuk bertingkah laku terhadap suatu perkara. Sikap berkaitan dengan identifikasi, keterlibatan dan kesetiaan, sedangkan kehendak bergantung pada keadaan untuk bertingkah laku dalam kesediaan menampilkan usaha.

Kinerja merupakan hasil kerja yang dapat dicapai oleh seseorang atau kelompok orang dalam sebuah perusahaan, sesuai dengan wewenang dan tanggung jawab masing-masing dalam rangka mencapai tujuan organisasi bersangkutan secara resmi sesuai dengan hukum dan sesuai dengan moral maupun etika. Rivai (2013:309), menyatakan kinerja merupakan hasil kerja wwith http://mahesainstitute.web.id/ojs2/index.php/jehss mahesainstitut@gmail.com 488 
konkret yang dapat diamati dan dapat diukur. Kinerja karyawan perlu dianalisis keberhasilan atau kegagalan dalam mencapai tujuan perusahaan.Kinerja karyawan yang dikaitkan dengan kepuasan dapat berlaku pada setiap perusahaan dan salah satunya perusahaan perkebunan PT. Mopoli Raya. Berdasarkan hasil penelitian terdahulu yang dilakukan terdapat beberapa variabel yang dapat mempengaruhi kinerja karyawan PT. Mopoli Raya diantaranya adalah kecerdasan emotional dan kompensasi (Syardiansah, dkk, 2018; Syardiansah, 2020).

Hasil observasi awal yang dilakukan melalui kunjungan ke perusahaan dengan melihat perusahaan dan keadaan karyawan yang bekerja. Selain melakukan observasi dilakukan wawancara dengan karyawan bagian sumber daya manusia di PT. Mopoli Raya untuk mendapatkan kondisi karyawan. Perusahaan perkebunan PT. Mopoli Raya yang memiliki karyawan dan karyawati yang siap bekerja dan mendukung kegiatan operasional perusahaan agar tujuan dari perusahaan tercapai. Dalam melaksanakan pekerjaan setiap karyawan yang merasa puas terhadap pekerjaannya akan menghasilkan kinerja yang maksimal dan berdampak positif terhadap kinerja perusahaan secara keseluruhan. Begitu pula halnya dengan memiliki komitmen kerja yang tinggi, maka kinerja karwayan akan menintkan karena setiap karyawan agar berusaha mencapai hasil yang maksimal sebagaimana yang diharapkan perusahaan.

Hasil wawancara yang dilakukan langsung dengan karyawan mengenai kepuasan kerja yang mereka rasakan, diketahui bahwa kepuasan kerja yang dirasakan, terdapat karyawan merasa kurang puas dengan imbalan yang diterimanya walau imbalan berupa gaji sudah sesuai dengan upah minimum provinsi, akan tetapi terdapat karyawan yang merasa kurang puas terhadap pendapatan yang diterima. Hal tersebut karena pendapatan yang diterima belum dapat memenuhi kebutuhan keluarga. Kepuasan kerja yang diterima selain dari imbalan, terdapat pula perilaku atasan yang dapat memberikan rasa puas terhadap pekerjaan. Terdapat karyawan yang merasa puas terhadap perilaku atasan yang selalu diperhatikan pekerjaannya dan memberikan bantuan saat mendapat kendala, akan tetapi terdapat pula karyawan yang kurang merasa puas terhadap perilaku atasan terutama hasil pekerjaan karyawan yang dinilai biasa saja dan ketika karyawan mendapat kendala tidak diberikan bantuan melainkan tetap harus menyelesaikan pekerjaan hingga tuntas.

Sejauh ini kepuasan kerja yang dirasakan karyawan pada PT, Mopoli Raya masih terdapat sesama karyawan yang kurang mendukung dalam setiap pekerjaannya. Hal tersebut diketahui dari karyawan yang merasa bekerja secara tim, harusnya menyelesaikan tugas bersama-sama akan tetapi terdapat rekan kerja yang mengharapkan rekan lainnya lebih aktif dalam menyelesaikan tugas-tugas tim.Selanjutnya imbalan yang diterima yang belum memberikan rasa puas pada diri karyawan dan perilaku atasan yang pilih kasih serta rekan kerja yang kurang mendukung memberikan dampak terhadap hasil kerja atau kinerja karyawan yang kurang maksimal.

Sedangkan dalam hal komitmen dapat dilihat bahwa setiap karyawan yang berkerja pada PT Mopoli Raya tentunya memiliki niat yang kuat dalam bekerja. Sehingga komitmen ini terbentuk dalam perilaku pekerja sendiri yang terus bekerja sesuai dengan kemampuan dan keinginan perusahaan agar dapat memberikan hasil yang maksimal dalam memajukan perusahaan.

\section{METODE PENELITIAN}

Populasi pada penelitian ini adalah karyawan tetap PT. Mopoli Raya yang berjumlah 479 orang. Teknik sampling yang digunakan dalam penelitian ini adalah probability sampling menggunakan simple random sampling yaitu teknik penentuan sampel acak sederhana. Adapun sampel dalam penelitian ini berjumlah 83 orang responden yang diperoleh menggunakan rumus Slovin dalam Sinulingga (2013).

Dimana:

$$
n=\frac{N}{1+N \cdot e^{2}}
$$

$\mathrm{n}=$ ukuran sampel 
$\mathrm{N}=$ ukuran populasi (479)

$\mathrm{e}=$ persen kelonggaran ketidaktelitian karena kesalahan pengambilan sampel $(10 \%)$

Teknik pengumpulan data dilakukan dengan observasi, merupakan pengamatan secara langsung terhadap objek yang akan dipelajari baik dalam lingkungan kerja alamiahnya maupun dalam laboratorium setting (Sinulingga, 2013:185). Observasi dilakukan untuk mendapatkan data lapangan dengan melihat langsung objek penelitian yaitu PT. Mopoli Raya di Kecamatan Seruway. Wawancara atau interview adalah salah satu teknik pengumpulan data dan informasi ialah melalui cara berkomunikasi secara langsung dengan pelanggan yaitu orang-orang tertentu yang ditetapkan sebagai sumber data (Sinulingga, 2013:175). Wawancara dilakukan langsung dengan pimpinan dan karyawanPT. Mopoli Raya. Dan dengan menyebarkan kuesioner, kuisioner merupakan tehnik pengumpulan data yang dilakukan dengan cara memberi seperangkat pertanyaan atau pernyataan tertulis kepada responden untuk dijawabnya (Sugiyono, 2012:199). Pernyataan variabel pada kuisioner dimasukkan ke dalam skala likert skor 1-5

Metode analisis data dalam penelitian ini adalah analisis regresi linier berganda dengan bantuan program SPSS. Adapun pengujian hipotesis dilakukan melalui Uji secara parsial (Uji t), dilakukan untuk menguji signifikansi hubungan antara variabel X dan $Y$, apakah X benar-benar berpengaruh terhadap variabel $\mathrm{Y}$. Uji secara simultan (Uji $\mathrm{F}$ ), dilakukan untuk menguji signifikansi hubungan antara variabel X1 dan X2 terhadap Y, secara simultan apakah X1 dan X2 dan benar-benar berpengaruh terhadap variabel $Y$.

Koefisien determinasi $\left(\mathrm{R}^{2}\right)$ dari hasil regresi berganda menunjukkan seberapa besar variabel terikat bisa dijelaskan oleh variabel bebasnya (Sunyoto, 2013:79). Koefisien determinasi $\left(\mathrm{R}^{2}\right)$ antara 0 (nol) dan 1 (satu). Koefisien determinasi $\left(\mathrm{R}^{2}\right)$ nol variabel independen sama sekali tidak berpengaruh terhadap variabel dependen. Apabila koefisien determinasi semakin mendekati satu, maka dapat dikatakan bahwa variabel independen berpengaruh terhadap variabel dependen.

\section{HASIL DAN PEMBAHASAN}

Berdasarkan pengolahan data yang diperoleh dari hasil penyebaran kuesioner terhadap 83 orang karyawan PT Mopoli Raya selaku responden, didapatkan bahwa:

Tabel 1 Hasil Uji Regresi Linear Berganda

\begin{tabular}{|c|c|c|c|c|c|c|}
\hline & \multirow[t]{2}{*}{ Model } & \multicolumn{2}{|c|}{ Unstandardized Coefficients } & \multirow{2}{*}{$\begin{array}{c}\text { Standardized Coefficients } \\
\text { Beta }\end{array}$} & \multirow[t]{2}{*}{$\mathrm{t}$} & \multirow[t]{2}{*}{ Sig. } \\
\hline & & $\mathrm{B}$ & Std. Error & & & \\
\hline \multirow{3}{*}{1} & (Constant) & 1,314 &, 543 & & 2,417 & ,018 \\
\hline & Komitmen Kerja &, 140 & ,111 & ,111 & 1,258 &, 212 \\
\hline & Kepuasan Kerja & ,557 & , 080 & 613 & 6,965 & , 000 \\
\hline
\end{tabular}

Dari tabel 1 hasil uji regresi linear berganda diproleh model regresi linier yaitu $Y=1,314+$ $0,140 \mathrm{X}_{1}+0,557 \mathrm{X}_{2}$. Dari persama ini dapat diterjemahkan bahwa konstanta sebesar 1,314 adalah nilai kinerja karyawan tanpa adanya nilai variabel komitmen kerja dan kepuasan kerja dalam penelitian ini. Sedangkan nilai koefisien regresi variabel komitmen kerja sebesar 0,140 dan bernilai positif, dapat diartikan setiap penambahan 1 satuan nilai koefisien variabel komitmen kerja maka kinerja karyawan akan bertambah sebanyak 0,140 satuan. Dan nilai koefisien regresi variabel kepuasan kerja sebesar 0,557 dan bernilai positif, dapat diartikan setiap penambahan 1 satuan nilai koefisien variabel kepuasan kerja maka kinerja karyawan akan bertambah sebanyak 0,140 satuan. Adapun hasil uji t atau uji signifikan variabel komitmen kerja terhadap kinerja karyawan dapat diketahui bahwa nilai t sig. variabel komitmen kerja sebesar 0,212 berbanding dengan alpha sebesar 0,05, karena nilai t sig. 0,212>0,05 maka dapat dinyatakan bahwa variabel komitmen kerja berpengaruh tidak signifikan terhadap kinerja karyawan PT Mopoli Raya. Sedangkan hasil uji t atau uji signifikan variabel kepuasan kerja terhadap kinerja karyawan dapat diketahui bahwa nilai t sig. variabel kepuasan kerja sebesar 0,000 berbanding dengan alpha 
Zulkarnen Mora, Icha Fandayani, Agung Suharyanto. Pengaruh Komitmen Kerja dan Kepuasan kerja Terhadap Kinerja Karyawan PT Mopoli Raya Di Kecamatan Seruway

sebesar 0,05, karena nilai t sig. 0,000<0,05 maka dapat dinyatakan bahwa variabel kepuasan kerja berpengaruh signifikan terhadap kinerja karyawan PT Mopoli Raya.

Tabel 2 ANOVA

\begin{tabular}{|c|c|c|c|c|c|c|}
\hline \multirow[t]{2}{*}{ Model } & & Sum of & $\mathrm{df}$ & Mean Square & $\mathrm{F}$ & Sig. \\
\hline & Regression & 7,779 & 2 & 3,890 & 24,667 & ,000 \\
\hline \multirow[t]{2}{*}{1} & Residual & 12,615 & 80 & 158 & & \\
\hline & Total & 20,394 & 82 & & & \\
\hline
\end{tabular}

Dari tabel 2 diperoleh hasil pengujian signifikansi secara sumultan terhadap variabel X1 dan X2 terhadap Y. Dimana hasil diperoleh bahwa nilai signifikansi $\mathrm{F}$ sig sebesar 0,000 berbanding dengan alpha sebesar 0,05, karena nilai $\mathrm{F}$ sig $0,000<0,05$ maka dapat dinyatakan bahwa variabel komitmen kerja (X1) dan kepuasan kerja (X2) secara simultan berpengaruh signifikan terhadap kinerja karyawan PT Mopoli Raya.

Pada tabel 3 diperlihatkan nilai koefisien determinasi $\left(\mathrm{R}^{2}\right)$ variabel komitmen kerja dan kepuasan kerja sebesar 0,381. Artinya variabel independen (komitmen kerja dan kepuasan kerja) hanya memiliki pengaruh sebesar $38,1 \%$ terhadap variabel dependen (kinerja karyawan) pada PT Mopoli Raya, sedangkan sisanya dipengaruhi oleh variabel lain seperti kompensasi dan kecerdasan emosional (Syardiansah, dkk, 2018; Syardiansah, 2020).

Tabel 3 Koefisien Determinasi

\begin{tabular}{ccccc}
\hline Model & $\mathrm{R}$ & R Square & Adjusted R Square & Std. Error of the Estimate \\
\hline 1 &, 618 &, 381 &, 366 &, 39710 \\
\hline \multicolumn{4}{c}{ Sumber: Data Primer diolah (2019) }
\end{tabular}

\section{SIMPULAN}

Sesuai penelitian yang dilakukan dengan melakukan pengalohan data dan anailisis data, maka dapat ditarik kesimpulan persamaan regresi dalam penelitian ini yaitu $Y=1,314+0,140 X 1$ $+0,557 \mathrm{X} 2$, dimana konstanta senilai 1,314 merupakan nilai kinerja karyawan tanpa nilai variabel bebas. Sedangkan nilai variabel komitmen kerja sebesar 0,140 artinya setiap peningkatan satu satuan maka nilai kinerja karyawan meningkat sebesar 0,140 dan nilai variabel kepuasan kerja sebesar 0,557 artinya setiap peningkatan satu satuan maka nilai kinerja karyawan meningkat sebesar 0,557. Hasil uji parsial menunjukkan bahwa variabel komitmen kerja berpengaruh tidak signifikan terhadap kinerja karyawan dan variabel kepuasan kerja berpengaruh signifikan terhadap kinerja karyawan. Sedangkan secara simultan variabel komitmen kerja dan kepuasan kerja berpengaruh signifikan terhadap kinerja karyawan. Nilai koefisien determinasi variabel komitmen kerja dan kepuasan kerja sebesar 0,381 berarti variabel independen hanya memiliki pengaruh sebesar 38,1\% terhadap variabel dependen pada PT Mopoli Raya di Kecamatan Seruway.

\section{DAFTAR PUSTAKA}

Arikunto, S. (2010). Prosedur Penelitian. Jakarta: Rineka Cipta.

Amalia, K. (2012). Pengaruh Kepuasan Kerja terhadap Kinerja Karyawan pada Agen PT. Jasaraharja Putera Cabang Jakarta.Skripsi.Universitas Indonesia.Depok.

Gomes, C.F. (2012). Manajemen Sumber Daya Manusia. Yogyakarta: Andi.

Hasibuan, M. (2016). Manajemen Sumber Daya Manusia.Edisi Revisi. Jakarta: Bumi Aksara.

Irawan, C. (2012). Pengaruh Kepuasan Kerja terhadap Kinerja Karyawan pada PT. Rafi Kemajaya Abadi.Jurnal Manajemen Motivasi.Vol.1, No.1 Hal.668-672.

Kasmir. (2016). Manajemen Sumber Daya Manusia. Jakarta: Raja Grafindo Persada.

Luthans, F. (2010). Perilaku Organisasi. Yogyakarta: Andi.

Mangkunegara, A. P. (2015). Manajemen Sumber Daya Manusia.Bandung: Remaja Rosda Karya.

Mora, Z., Junaida, E., dan Fuad, M. (2017). Konflik Kerja-Keluarga dan Kepuasan Kerja Pegawai Perempuan: Studi pada Pegawai Negeri Sipil di Aceh Timur. Jurnal Ekonomi dan Bisnis Islam. Vol 2. No. 1. Hal 113.

Munandar, A.S. (2008). Psikologi Industri dan Organisasi. Jakarta: UI-Press.

Notoatmodjo, S. (2011).Pengembangan Sumber Daya Manusia. Jakarta: Rineka Cipta. 
Nurlaila. (2010).Manajemen Sumber Daya Manusia. Bandung: Aditama.

Risqi, R.O, Mirwan, U., dan Wahyu, S. (2015). Analisis Pengaruh Kepuasan Kerja terhadap Kinerja Karyawan dengan Pendekatan Kansei Engineering Perusahaan XYZ. Jurnal Agritech.Vol 35.No. 1 Hal.78-87.

Rivai, V, dan Sagala E.J. (2013). Manajemen Sumber Daya Manusia untuk Perusahaan. Jakarta: Rajawali Pers.

Robbins, S. P. (2013). Perilaku Organisasi. Jakarta: Indeks.

Sedarmayanti. 2012.Sumber Daya Manusia dan Produktivitas Kerja. Bandung: Mandar Maju.

Sinulingga, S. (2013). Metode Penelitian Edisi 3. Medan: USU Pres.

Situmorang, S.H., dan Lufti, M. (2014). Analisis Data untuk Riset Manajemen dan Bisnis. Medan: USU Press.

Sugiyono. (2012).Statistik Untuk Penelitian. Bandung: Alfabeta.

Sunyoto, D. (2013).Sumber Daya Manusia. Jakarta: PT. Caps.

Suwatno dan Priansa, J. (2011). Manajemen SDM dalam Organisasi Publik dan Bisnis. Bandung: Alfabeta.

Syardiansah, S, H. (2018). Pengaruh Kompensasi Terhadap Kinerja Karyawan PT Mopoli Raya Di Kecamatan Seruway. Jurnal Ilmiah Sains, Tenologi, Ekonomi, Sosial dan Budaya, Vol. 2, No. 4, Hal. 79 $-82$

Syardiansah, L., A., Daud, M. N., Windi, \& Suharyanto, A. (2020). The Effect of Job Satisfaction and Organizational Culture on Employee Performance of the Royal Hotel in East Aceh District. Budapest International Research and Critics Institute Journal, Vol. 3, No. 2, Hal. 118-126

Syardiansah (2020). Pengaruh Kecerdasan Emotional Terhadap Kinerja Karyawan PT. Mopoli Raya Kecamatan Pematang Jaya. Journal of Education, Humaniora and Social Sciences (JEHSS). 3 (1): 8-13

Tobing, D., Sulianti K.L. (2014).Pengaruh Komitmen Organisasional dan Kepuasan Kerja terhadap Kinerja Karyawan PT. Perkebunan Nusantara III di Sumatera Utara.Jurnal Manajemen dan Kewirausahaan.Vol 11.No. 1, Hal.31-37.

Wibowo. (2014). Manajemen Kinerja. Jakarta:PT Raja Grafindo Persada.

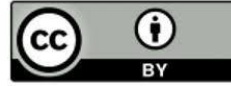

